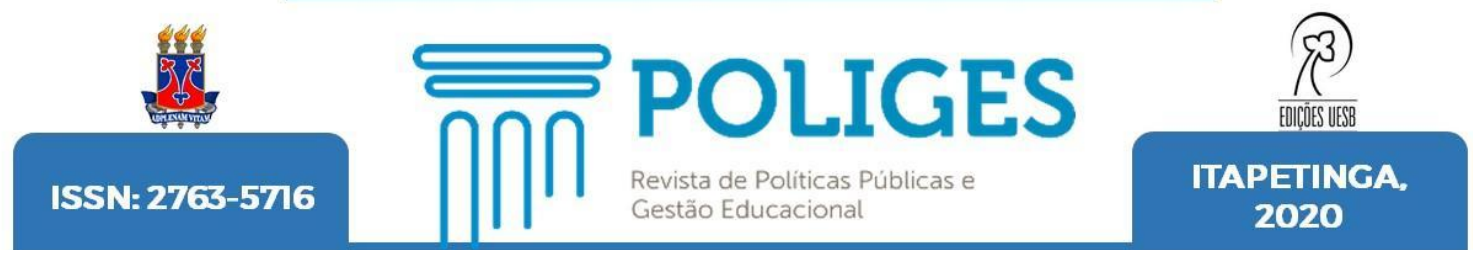

\title{
AÇÕES DE GOVERNO PARA AS POLÍTICAS DE EDUCAÇÃO EM GÊNERO E SEXUALIDADE DO ESTADO DO CEARÁ (2015-2018)
}

\author{
GOVERNMENT ACTIONS FOR GENDER AND SEXUALITY'S EDUCATION \\ POLICIES IN THE STATE OF CEARÁ (2015-2018)
}

\section{ACCIONES DEL GOBIERNO PARA POLÍTICAS DE EDUCACIÓN DE GÉNERO Y SEXUALIDAD EN EL ESTADO DE CEARÁ (2015-2018)}

Homero Henrique de Souza

ORCID iD: https://orcid.org/0000-0002-0730-3210

Doutorando em Sociologia (UECE) - SEC-CE - Brasil

Arliene Stephanie Menezes Pereira

ORCID iD: https://orcid.org/0000-0002-3042-538X

Doutoranda em Educação (UECE) - Instituto Federal do Ceará - Brasil

Ana Carolina Braga de Sousa

ORCID iD: https://orcid.org/0000-0001-6959-5493

Doutoranda em Educação (UFC) - Secretaria de Educação do Ceará - Brasil

Zuleide Fernandes de Queiroz

ORCID iD: https://orcid.org/0000-0003-3174-4750

Pós-doutora em Educação (UFRN) - Universidade Regional do Cariri - Brasil

Resumo: As temáticas da diversidade de gênero e sexualidade na educação adquirem cada vez maior visibilidade, suscitando discussões e reflexões na grande mídia, redes sociais, dos movimentos sociais e nas salas de aula; provocando diversas reações e gerando iniciativas e orientações a serem praticadas numa perspectiva de afirmação democrática, respeito mútuo, aceitação da diferença e construção de uma sociedade em que todos possam exercer plenamente sua cidadania. O presente texto trata da Política Pública de Educação do Estado do Ceará para Gênero e Sexualidade na Escola desenvolvidas entre os anos de 2015 e 2018 (Governo Camilo Santana) pela Secretaria da Educação do Estado do Ceará (Seduc). Objetivando descrever as principais ações desenvolvidas pela Seduc, dentro deste recorte temporal, para as políticas de educação em gênero e sexualidade no Estado do Ceará. Em termos de procedimentos metodológicos, a pesquisa baseou-se em 
dados levantados a partir da análise documental de planos de trabalho, relatórios, dossiês e mensagens governamentais disponibilizados pela Seduc e a página eletrônica do governo do Estado do Ceará. A partir da sistematização dos dados coletados, foi realizada a interpretação por meio da categorização mediante a análise de conteúdo (Bardin,1977). Os resultados apontam que a política de formação pedagógica com o recorte temático citado é inovadora, relevante e, sobretudo, uma política de resistência, porém insipiente e desarticulada. E que a política educacional do estado do Ceará carece de maior conhecimento e aplicabilidade dentro do cotidiano escolar, pois ainda não é prioritária dentro da agenda governamental e de alcance limitado.

Palavras chave: Gênero. Sexualidade. Políticas Públicas Educacionais

Abstract: The themes of gender and sexuality diversity in education gain increasing visibility, giving rise to discussions and reflections in the mainstream media, social networks, social movements and in classrooms; provoking diverse reactions and generating initiatives and orientations to be practiced in a perspective of democratic affirmation, mutual respect, acceptance of difference and construction of a society in which everyone can fully exercise their citizenship. This text deals with the Public Education Policy of the State of Ceará for Gender and Sexuality at School developed between the years 2015 and 2018 (Government Camilo Santana) by the Secretary of Education of the State of Ceará (Seduc). Aiming to describe the main actions developed by Seduc, within this time frame, for education policies in gender and sexuality in the State of Ceará. In terms of methodological procedures, the research was based on data collected from the documentary analysis of work plans, reports, dossiers and government messages made available by Seduc and the website of the government of the State of Ceará. From the systematization of the collected data, interpretation was performed through categorization through content analysis (Bardin, 1977). The results show that the pedagogical training policy with the aforementioned theme is innovative, relevant and, above all, a resistance policy, however incipient and disjointed. And that the educational policy of the state of Ceará lacks greater knowledge and applicability within the school routine, as it is not yet a priority within the governmental agenda and of limited scope.

Keywords: Genre. Sexuality. Public Education Policy

Resumen: Los temas de diversidad de género y sexualidad en la educación cobran cada vez más visibilidad, dando lugar a discusiones y reflexiones en los principales medios de comunicación, redes sociales, movimientos sociales y en las aulas; provocando reacciones diversas y generando iniciativas y orientaciones para ser practicadas en una perspectiva de afirmación democrática, respeto mutuo, aceptación de la diferencia y construcción de una sociedad en la que todos puedan ejercer plenamente su ciudadanía. Este texto trata de la Política de Educación Pública del Estado de Ceará para Género y Sexualidad en la Escuela desarrollada entre los años 2015 y 2018 (Gobierno Camilo Santana) por la Secretaría de Educación del Estado de Ceará (Seduc). Con el objetivo de describir las principales acciones desarrolladas por Seduc, en este marco temporal, para las políticas de educación en género y sexualidad en el Estado de Ceará. En cuanto a los procedimientos metodológicos, la investigación se basó en datos recolectados del análisis documental de planes de trabajo, informes, expedientes y mensajes gubernamentales puestos a disposición por Seduc y el sitio web del gobierno del Estado de Ceará. A partir de la sistematización de los datos recolectados, se realizó la interpretación mediante la categorización a través del

Revista de Políticas Públicas e Gestão Educacional (POLIGES) - UESB-Itapetinga. ISSN: 2763-5716Ano 2020, Volume 1, número 1, set. - dez. de 2020. 
análisis de contenido (Bardin, 1977). Los resultados muestran que la política de formación pedagógica con la temática mencionada es innovadora, relevante y, sobre todo, una política de resistencia, por insipiente e inconexa que sea. Y que la política educativa del estado de Ceará carece de mayor conocimiento y aplicabilidad dentro de la rutina escolar, ya que aún no es una prioridad dentro de la agenda gubernamental y de alcance limitado.

Palabras clave: Género. Sexualidad. Política de Educación Pública

\section{Introdução}

O presente texto trata sobre a Política Pública de Educação do Estado do Ceará para Gênero e Sexualidade na Escola desenvolvidas entre os anos de 2015 e 2018 (Governo Camilo Santana) pela Secretaria da Educação do Estado do Ceará (Seduc).

O objetivo deste artigo é descrever as principais ações desenvolvidas pela Seduc, no período supracitado, para as políticas de educação em gênero e sexualidade no Estado do Ceará. Em termos de procedimentos metodológicos, a pesquisa baseou-se em dados levantados a partir da análise documental de planos de trabalho, relatórios, dossiês e mensagens governamentais disponibilizados pela Secretaria de Educação e a página eletrônica do governo do Estado do Ceará.

A partir da sistematização dos dados coletados, a interpretação destes foi realizada por meio da categorização mediante a análise de conteúdo (BARDIN,1977). As categorias de análise, por sua vez, foram definidas de acordo com a descrição das ações governamentais desenvolvidas: 1 - Mobilização, sensibilização e divulgação das ações da Educação, Gênero e Sexualidade (EGS) junto às Coordenadorias Regionais de Desenvolvimento da Educação (Crede), Superintendências das Escolas Estaduais de Fortaleza (Sefor) e demais coordenadorias da Seduc-sede; 2 - Articulação com Organizações Governamentais (OGs), Organizações Não Governamentais (ONGs) e movimentos que atuam a favor da diversidade sexual; e 3 - Desenvolvimento e apoio a projetos curriculares que promovam a igualdade de gênero, o respeito à diversidade sexual e à dignidade humana desenvolvidos em todas as escolas.

Revista de Políticas Públicas e Gestão Educacional (POLIGES) - UESB-Itapetinga. ISSN: 2763-5716Ano 2020, Volume 1, número 1, set. - dez. de 2020. 


\section{Análise documental na interface com as ações desenvolvidas}

As temáticas da diversidade de gênero e sexualidade na educação vêm adquirindo cada vez maior visibilidade, suscitando discussões e reflexões na grande mídia, nas redes sociais, dos movimentos sociais e nas salas de aula. São temas que provocam diversas reações, assim como geram iniciativas e orientações a serem praticadas numa perspectiva de afirmação democrática, respeito mútuo, aceitação da diferença e construção de uma sociedade em que todos possam exercer plenamente sua cidadania. O desafio do sistema de ensino é colocar no centro da política pública o valor das diferenças e da diversidade com seus conteúdos de gênero, identidade de gênero e de orientação sexual, ante um cenário de desconhecimento e interpretações equivocadas que asseveram o preconceito e a discriminação.

As atuais Resoluções do Conselho Nacional de Educação (Res. CNE/CEB nº 02/2012) estabelecem as Diretrizes Curriculares Nacionais, orientando a construção de um sistema educacional inclusivo, que garanta o direito universal de acesso à escolarização e assegure, como parte integrante desse direito, o respeito e a valorização da diversidade.

Nesse contexto, na perspectiva de formular e implementar políticas públicas voltadas para a valorização das diferenças e da diversidade, e de promover uma educação inclusiva marcada nos princípios dos direitos humanos, a Seduc tem como objetivo estratégico "fortalecer a escola como espaço de inclusão, de respeito à diversidade e de promoção da cultura da paz" (SEDUC, s/d).

Por meio do Decreto $n^{\circ} 31.221$, de 03 de junho de 2013 ${ }^{1}$, a Seduc constituiu na sua estrutura organizacional, uma Coordenadoria de Desenvolvimento da Escola e da Aprendizagem (Codea) com a área da Diversidade e Inclusão Educacional. É nessa Coordenadoria que desde abril de 2015, a subárea de Educação, Gênero e

\footnotetext{
${ }^{1}$ Publicado no Diário Oficial do Estado em de 06 de junho de 2013. Disponível em: http://www.casacivil.ce.gov.br/diario-oficial/
}

Revista de Políticas Públicas e Gestão Educacional (POLIGES) - UESB-Itapetinga. ISSN: 2763-5716Ano 2020, Volume 1, número 1, set. - dez. de 2020. 
Sexualidade ${ }^{2}$ passou a atender pelas ações políticas governamentais da temática em questão.

De posse dos planos de trabalho de 2015 a 2017 fornecidos pela Secretaria, constatou-se que estes se pautavam em quatro grandes ações: Criação e consolidação da subárea Educação, Gênero e Sexualidade (EGS) na estrutura organizacional da Codea/Diversidade/Inclusão; Mobilização, sensibilização e divulgação das ações da EGS junto às Crede/Sefor e demais coordenadorias da Seduc sede; Desenvolvimento e apoio a projetos curriculares que promovessem a igualdade de gênero, o respeito à diversidade sexual e à dignidade humana desenvolvidos em todas as escolas; Articulação com organizações governamentais (OGs) e Organizações Não Governamentais (ONGs) e movimentos que atuam a favor da diversidade sexual.

Para o ano de 2018 essas quatro grandes ações foram reescritas, tendo como base as metas educacionais previstas no Plano Estadual de Enfrentamento a LGBTfobia e promoção dos Direitos Humanos de $\mathrm{LGBT}^{3}$ do Estado do Ceará (Decreto $n^{\circ}$ 32.188/17): Elaboração e implementação de uma política de formação, que contenha ações pontuais e continuadas dos profissionais da educação (professores/as, gestores/as, funcionários/as, técnicos/as e apoio) da rede pública estadual e conselheiros escolares, acerca da sexualidade, da diversidade de orientação sexual, da identidade de gênero e da promoção da cidadania da população LGBT; Realização de pesquisas para avaliar o grau de LGBTfobia ${ }^{4}$ nas escolas públicas do estado do Ceará, cujos resultados devem ser divulgados e

\footnotetext{
${ }^{2}$ A Codea passou a ser denominada Coordenadoria de Diversidade e Inclusão Educacional - Codin e a subárea (equipe) de Educação, Gênero e Sexualidade (EGS) foi renomeada de Educação, Direitos Humanos, Gênero e Sexualidade (EDHGS).

${ }^{3}$ São muitas as representações envolvidas, além das várias mudanças na sigla representativa desse movimento no Brasil. A mais comum, GLS (Gays, Lésbicas e Simpatizantes) foi substituída por GLBT (com a inclusão de Bissexuais e Transgêneros e exclusão dos Simpatizantes). A sigla aqui adotada, LGBT (Lésbicas, Gays, Bissexuais, Travestis, Transexuais e Transgêneros), segue deliberação da I Conferência Nacional LGBT, realizada em 2008 (VIANNA, 2015, p.794).

${ }^{4} \mathrm{O}$ termo LGBTfobia é categoria êmica tendo sido reivindicada pelo movimento organizado de lésbicas, travestis e transexuais sob o argumento de que a palavra homofobia inviabiliza as violências investidas contra outros segmentos para além dos gays (FEITOSA, 2017, p.22). Em respeito a diversidade de posições no interior do Movimento LGBT, utilizarei de maneira alternada tanto LGBTfobia como homofobia, considerando a capilaridade que esta última alcançou frente a setores mais amplos tanto no campo dos estudos LGBT quanto no campo social denominado "senso comum".
}

Revista de Políticas Públicas e Gestão Educacional (POLIGES) - UESB-Itapetinga. ISSN: 2763-5716Ano 2020, Volume 1, número 1, set. - dez. de 2020. 
socializados, especialmente junto às redes de educação; Elaboração de material didático que considere as diversidades, as orientações sexuais e as identidades de gênero; Realização de campanhas e eventos que tratem sobre as diversidades de gênero e sexuais (CEARÁ, 2017).

Esse plano resultou dos debates entre órgãos governamentais e sociedade civil durante a III Conferência Estadual LGBT do Ceará ${ }^{5}$ realizada em fevereiro de 2016. Na oportunidade, as resoluções reverteram-se em metas e propostas de políticas públicas para o combate às discriminações contra pessoas LGBT. O documento foi dividido em seis áreas temáticas: 1 - educação; 2 - políticas intersetoriais e participação popular; 3 - cultura e comunicação em direitos humanos; 4 - segurança pública e sistemas de Justiça na promoção e defesa dos direitos humanos da população LGBT; 5 - promoção da cidadania e enfrentamento da violência contra a população LGBT; 6 - marcos jurídicos e normativos para o enfrentamento à violência contra a população LGBT. A principal diretriz da área de Educação foi a inserção da temática LGBT no sistema de educação básica e superior, sob a abordagem que promova o respeito e o reconhecimento da diversidade da orientação sexual e identidade de gênero.

Observou-se nos planos de trabalho de 2015 a 2017 que havia a intenção de se criar um grupo de trabalho interinstitucional para a elaboração de diretrizes estaduais voltadas a educação sexual, gênero e diversidade, porém essa articulação foi abortada frente a conjuntura política adversa que se estabeleceu com a aprovação do Plano Estadual de Educação em maio de $2016^{6}$.

Após meses tramitando na Assembleia Legislativa $(A L)$ do Estado do Ceará e tendo recebido aproximadamente 150 emendas entre aditivas, modificativas e supressivas, o PEE do Ceará foi finalmente votado no dia 05 de maio de 2016. Cento e vinte uma (121) emendas foram incorporadas ao texto original. Itens que tratavam de educação de gênero e sexualidade e do combate à discriminação por orientação sexual foram os mais discutidos. Parlamentares

\footnotetext{
${ }^{5}$ Fonte:

https://www.casacivil.ce.gov.br/2016/03/23/conferencia-estadual-de-politicas-publicas-edireitos-human os-para-lgbt-define-delegados/

${ }^{6}$ Ver Souza, 2016. Plano Estadual de Educação do Ceará: Gênero e Sexualidade entre avanços e retrocessos Disponível em:

http://www.editorarealize.com.br/revistas/conedu/trabalhos/TRABALHO_EV056_MD1_SA11_ID2621_ 11082016151533.pdf
}

Revista de Políticas Públicas e Gestão Educacional (POLIGES) - UESB-Itapetinga. ISSN: 2763-5716Ano 2020, Volume 1, número 1, set. - dez. de 2020. 
conservadores e fundamentalistas ligados a grupos religiosos e seus aliados articularam a retirada de todos os termos que faziam referência às populações de lésbicas, gays, bissexuais, travestis e transexuais (LGBT) e as temáticas das diversidades sexuais. A maior parte dos textos das metas e estratégias que contemplavam a discussão de gênero e sexualidade foram alteradas e "remendadas" com o art. 14 da Constituição Estadual do Ceará que preconiza: defesa da igualdade e combate a qualquer forma de discriminação em razão de nacionalidade, condição e local de nascimento, raça, cor, religião, origem étnica, convicção política ou filosófica, deficiência física ou mental, doença, idade, atividade profissional, estado civil, classe social, sexo e orientação sexual (SOUZA, 2016, p.6-7).

A retirada dos termos relacionados a gênero e sexualidade foi uma tentativa de invisibilizar, enfraquecer as políticas públicas para essas áreas, entretanto não as silenciaram de maneira proibitiva. Paralelo a essa situação, o processo de ocupação das escolas estaduais, liderado principalmente por estudantes LGBT e meninas durante a greve de professores, ocorrida no mesmo ano de 2016, deu uma maior visibilidade ao trabalho que a equipe ${ }^{7}$ EGS vinha desenvolvendo.

Antes de detalhar as ações desenvolvidas e resultados atingidos pela subárea EGS da Seduc, no período de 2015 a 2018, é importante descrever a seguir as contribuições elaboradas por essa subárea e aprovadas para o Documento síntese do Plano de Governo Os 7 Cearás $^{8}$ da gestão Camilo Santana (2015/2018). Essas contribuições constam no rol de propostas para a Educação em Direitos Humanos do Ceará do Conhecimento $^{8}$ (p.193):

Favorecer a inclusão da educação em direitos humanos nos projetos político-pedagógicos das escolas, adotando as práticas pedagógicas democráticas presentes no cotidiano e inserindo a educação em

\footnotetext{
7 Dentro da estrutura organizacional da Codea/Diversidade e Inclusão educacional cada subárea responsável por uma política pública é denominada de "Equipe". Para evitar uma repetição exaustiva irei alternar ao longo do texto as palavras "equipe" e "subárea" como termos sinônimos. ${ }^{8}$ Disponível em: http://ptceara.org.br/images/conteudo/file/1_PlanodeGovernoCE2014.pdf

${ }^{8} \mathrm{O}$ Ceará do Conhecimento constrói os alicerces para uma sociedade esclarecida e inovadora, nos quais se sustentam os pilares de uma economia mais avançada, em uma estratégia de estímulo a um salto de qualidade no perfil socioeconômico do Ceará. Na busca desse propósito educacional, o Governo do Ceará trabalha para proporcionar uma formação integral de qualidade, em cinco temas estratégicos: Educação Básica, Educação Profissional, Ensino Superior, Ciência, Tecnologia e Informação e Cultura. Disponível em: (https://www.ceara.gov.br/projeto/educacao-cultura-ceara-do-conhecimento/)
}

Revista de Políticas Públicas e Gestão Educacional (POLIGES) - UESB-Itapetinga. ISSN: 2763-5716Ano 2020, Volume 1, número 1, set. - dez. de 2020. 
direitos humanos nas diretrizes curriculares da educação básica estadual; - Construir parcerias com os diversos membros da comunidade escolar na implementação da educação em direitos humanos; · Fomentar a inclusão, no currículo escolar, das temáticas relativas a gênero, identidade de gênero e orientação sexual como forma de combater todas as formas de discriminação e violações de direitos humanos, assegurando a formação continuada dos(as) trabalhadores(as) da educação para lidar criticamente com esses temas; · Apoiar a implementação de projetos culturais e educativos de enfrentamento a todas as formas de discriminação e violações de direitos no ambiente escolar; - Manter um permanente espaço de diálogo com instituições e ONG que desenvolvam ações voltadas para a população jovem LGBT; · Desenvolver e fortalecer políticas públicas de educação, comprometidas com o combate à discriminação de gênero e sexualidade e valorização das diferenças.

Essas propostas elaboradas pela EGS da Seduc foram votadas e defendidas em plenária com representações de movimentos sociais, técnicos educacionais, educadores universitários e sindicalistas, em novembro de 2014, e consolidadas e publicadas logo no início do primeiro mandato do governo Camilo Santana (2015-2018). As ações desenvolvidas pela subárea da Seduc estruturaram-se basicamente nas propostas de favorecer a inclusão da educação em direitos humanos, nos Projetos Político-Pedagógicos (PPP) das escolas, adotando as práticas pedagógicas democráticas presentes no cotidiano e inserindo a educação em direitos humanos nas diretrizes curriculares da educação básica estadual; fomentar a inclusão, no currículo escolar, das temáticas relativas a gênero, identidade de gênero e orientação sexual, como forma de combater todas as formas de discriminação e violações de direitos humanos, assegurando a formação continuada dos(as) trabalhadores(as) da educação, para lidar criticamente com esses temas; e desenvolver e fortalecer políticas públicas de educação comprometidas com o combate à discriminação de gênero e sexualidade e valorização das diferenças. 


\section{Mobilização,sensibilização e divulgação das ações da EGS junto às Crede/Sefor e demais coordenadorias da Seduc sede}

Dentro dessa ação, foi mobilizado um apoio à implementação do uso do nome social por alunos e alunas travestis e transexuais nas escolas da rede estadual, através da divulgação e orientação das Portarias $n^{0} 1435 / 2016^{9}$ e $n^{0} 1371 / 2017^{10}$ do Gabinete da Secretaria da Educação; da Resolução CEE/CEB n 463/2017 do Conselho Estadual de Educação do Ceará; do Decreto Estadual n 32.226/2017 e da Resolução CNE n 01/2018 que versam sobre o uso do nome social de pessoas travestis e transexuais nos espaços escolares. Esses dispositivos e outros (Resolução CNCD/SDH-PR $n^{\circ}$ 12/2015) eram sistematicamente trabalhados nas formações de professores.

Também, como atividade permanente, houve o mapeamento dos marcos legais de âmbito nacional e estadual, relacionados às questões de gênero e sexualidade, organizados e atualizados pelos integrantes da subárea. Essa documentação era sempre divulgada nos momentos de formação nas Crede/Sefor, escolas e Secretarias Municipais.

As formações eram agendadas via ofício e se realizavam entre duas a três formações, em média, semanalmente. Para fortalecer essa divulgação, enviava-se por e-mail e como documento impresso por malote, cópias dos decretos e resoluções que subsidiam questões quanto ao uso do nome social e dos banheiros por pessoas transexuais e travestis, pois fomentava a discussão curricular de assuntos ligados a gênero e sexualidade e a instituição de eventos importantes como a Semana Maria da Penha e a Semana Janaína Dutra, em âmbitos escolares.

Nos anos de 2017 e 2018, em cumprimento às leis estaduais n¹4.820/10 (Semana Luís Palhano) ${ }^{11}$, Lei $n^{0} 16.044 / 16$ (Semana Maria da Penha nas escolas) ${ }^{12}$ e

\footnotetext{
${ }_{9}^{9}$ Publicada em 21/12/2016. Disponível em: https://www.casacivil.ce.gov.br/diario-oficial/

${ }_{10}$ Publicada em 18/12/2017. Disponível em: https://www.casacivil.ce.gov.br/diario-oficial/

11 Publicada em 22/12/2010. Disponível em:

https://www.al.ce.gov.br/legislativo/legislacao5/leis2010/14820.htm

12 Publicada no Diário Oficial do Estado de 30 de junho de

2016. Disponível em: http://www.casacivil.ce.gov.br/diario-oficial/
}

Revista de Políticas Públicas e Gestão Educacional (POLIGES) - UESB-Itapetinga. ISSN: 2763-5716Ano 2020, Volume 1, número 1, set. - dez. de 2020. 
lei $n^{0}$ 16.481/17 (Semana Janaína Dutra) ${ }^{13}$ foram realizados, pela subárea Educação, Gênero e Sexualidade, seminários temáticos sobre o Plano Estadual de combate à LGBTfobia, o combate a violência contra a mulher e o combate à LGBTfobia na escola, respectivamente, reunindo um público total de 356 participantes dentre gestores escolares, professores, estudantes e outros profissionais da educação.

\section{Articulação com Organizações Governamentais (OGs), Organizações Não Governamentais (ONGs) e movimentos que atuam a favor da diversidade sexual}

Essa articulação se deu através da participação nas ações da Coordenadoria Especial de Políticas Públicas LGBT (COELGBT); do Conselho Estadual de Defesa dos Direitos Humanos (CEDDH); da Coordenadoria Especial de Políticas Públicas para Mulheres (CEPAM) e das Conferências municipais, regionais e estaduais LGBT e de Direitos Humanos. A subárea de Educação, Gênero e Sexualidade também se fez presente em mesas de debate, mesas de abertura de eventos acadêmicos, entrevistas, comissão organizadora e publicação de trabalhos de 66 eventos realizados por universidades, Crede/Sefor e veículos de comunicação impressos e rádio/TV, no período de 2015 a 2018.

Em dezesseis eventos a subárea de EGS foi convidada, principalmente, por universidades, a participar como ouvinte de formações e seminários acadêmicos sobre direitos humanos da população LGBT, gênero e políticas públicas, educação não-sexista e discriminatória, mulher e violência, o que demonstra reconhecimento dos acadêmicos e valorização do trabalho da equipe no meio universitário. A equipe técnica também participou de dez mesas de debate promovidas por instituições de ensino superior, dentro e fora do estado do Ceará, com vistas a disseminar o trabalho desenvolvido nas seguintes temáticas: proposição para Políticas Públicas da Diversidade Sexual e Direitos LGBT, Direitos Humanos e Gênero: educação e pesquisa; gênero, sexualidade e subjetividades; LGBTfobia e dia internacional da mulher. A produção científica, igualmente, foi uma preocupação dos técnicos

\footnotetext{
${ }^{13}$ Publicada no Diário Oficial do Estado de 26 de dezembro de 2017. Disponível em: http://www.casacivil.ce.gov.br/diario-oficial/
}

Revista de Políticas Públicas e Gestão Educacional (POLIGES) - UESB-Itapetinga. ISSN: 2763-5716Ano 2020, Volume 1, número 1, set. - dez. de 2020. 
responsáveis pela subárea, produzindo, apresentando e publicando nove trabalhos em congressos, simpósios e colóquios acadêmicos ${ }^{14}$, com o objetivo de divulgar a política do Estado do Ceará e debater acerca de maneiras de promover e qualificar o trabalho com gênero e sexualidades nas escolas.

\section{Desenvolvimento e apoio a projetos curriculares que promovam a igualdade}

\section{de gênero, o respeito à diversidade sexual e à dignidade humana desenvolvidos em todas as escolas}

As ações de formação continuada constituídas por atividades pedagógicas, elaboração de material e oferta de cursos de capacitação estavam previstas inicialmente para atender a gestores escolares, professores e outros profissionais da educação, conforme prevê a estratégia $3.13^{15}$ do Plano Nacional de Educação (PNE); a estratégia $8.8^{16}$ do Plano Estadual de Educação (PEE) do Estado do Ceará e, a partir de 2017 e as metas educacionais do Plano Estadual de enfrentamento à LGBTfobia e promoção dos direitos humanos de LGBT do Estado do Ceará, Decreto n 32.188/17 (CEARÁ, 2017).

Entretanto, no ano de 2016, dentro do contexto da paralisação de atividades escolares em função da greve de professores da rede estadual, surgiram novas demandas. A greve de professores foi marcada por um denso processo de ocupação das escolas através de lideranças estudantis que reivindicavam melhorias nas condições físicas das escolas, na oferta de alimentação escolar, na qualidade das aulas e denunciavam situações de preconceito e discriminação de gênero

\footnotetext{
${ }^{14}$ II Congresso Nacional de Educação (CONEDU, 2015), Simpósio Temático do Curta O Gênero 2016, XII Colóquio sobre Questões Curriculares/VIII Colóquio Luso-Brasileiro de Currículo 2016, III Congresso Nacional de Educação (CONDEDU, 2016), XV ECHE/V ENHIME/ IV SINECGEO 2016, V Seminário Internacional Enlaçando Sexualidades 2017, V SENACEM 2018, XVII Congresso de História da Educação 2018 e IX CINABEH 2018.

${ }^{15}$ Implementar políticas de prevenção à evasão motivada por preconceito ou quaisquer formas de discriminação, criando rede de proteção contra formas associadas de exclusão (Lei no 13.005/2014 PNE).

${ }^{16}$ Garantir a formação inicial e continuada de professores, gestores e demais profissionais da educação para desenvolver uma cultura de acolhimento, respeito, inclusive quanto a todos os preconceitos e opressões em razão de sua orientação sexual (Lei no 16.025/2016 - PEE).
}

Revista de Políticas Públicas e Gestão Educacional (POLIGES) - UESB-Itapetinga. ISSN: 2763-5716Ano 2020, Volume 1, número 1, set. - dez. de 2020. 
vivenciadas no cotidiano educacional ${ }^{17}$. A partir dessa conjuntura, a gestão superior da Secretaria da Educação, liderada à época pelo secretário Idilvan Alencar ${ }^{18}$, solicitou um plano de ação específico de atendimento às escolas com ações de formação discente. Esse plano foi constituído por palestras, rodas de conversa e aulões preparatórios para o Enem, além das oficinas pedagógicas que já se encontravam em curso. Para o desenvolvimento das formações e dos conteúdos, eram elaborados folders, orientações pedagógicas e material didático, constantemente atualizado com vídeos, charges, tirinhas, estudos de caso, proposições de atividades, questões do Enem, planos de aula e também atividades elaboradas pelos participantes das oficinas pedagógicas. Atendendo a uma demanda dos gestores e professores capacitados pelas oficinas durante os anos de 2015 e 2016, foi ofertado, nos anos de 2017 e 2018, duas edições do curso de aperfeiçoamento Direitos Humanos em Gênero e Sexualidade ${ }^{19}$.

Esse curso, com carga horária de $200 h$, foi oferecido em sua $1^{\text {a }}$ edição com a parceria do Instituto UFC Virtual ${ }^{20}$ e na $2^{a}$ edição através do Centro de Educação à Distância (CED) de Sobral. Em 2017 o curso foi ministrado na modalidade semipresencial para um público de 120 educadores. No ano de 2018, por falta de recursos financeiros, esse mesmo curso foi realizado totalmente a distância atendendo dessa vez 110 educadores. Nas duas edições, os tutores do curso foram os próprios técnicos da subárea de Educação, Gênero e Sexualidade.

Durante os quatro anos de atuação (2015-2018), foram realizadas 213 formações pedagógicas (57 oficinas pedagógicas, 77 palestras temáticas, 31 rodas

\footnotetext{
${ }^{17}$ Fonte:

http://g1.globo.com/ceara/noticia/2016/04/alunos-ocupam-escola-de-fortaleza-em-apoiogreve-de-prof e ssores.html

http://g1.globo.com/ceara/noticia/2016/05/estudantes-ocupam-34-escolasem-fortaleza-e-11-no-interior -do-ceara.html

${ }^{18} \mathrm{Em}$ reunião solicitada pelo então secretário Idilvan Alencar, o mesmo expôs sua preocupação com as inúmeras denúncias e relatos que recebera das lideranças estudantis envolvidas no processo de ocupação das escolas estaduais em 2016 sobre casos de preconceito, discriminação e assédio, especialmente contra estudantes meninas, negros e LGBTs, dentro dos espaços escolares. A partir dessa conjuntura, o trabalho de formação pedagógica em desenvolvimento pela equipe EGS intensificou-se no atendimento às escolas promovendo atividades diretamente com os estudantes.

${ }^{19}$ Fonte:

http://www.ced.seduc.ce.gov.br/index.php/noticias-anteriores/3062cedabreinscricoescursodireitoshum anos

${ }^{20}$ Instituto da Universidade Federal do Ceará (UFC).
}

Revista de Políticas Públicas e Gestão Educacional (POLIGES) - UESB-Itapetinga. ISSN: 2763-5716Ano 2020, Volume 1, número 1, set. - dez. de 2020. 
de conversa e 48 aulões Enem) envolvendo Credes/Sefor, escolas, Secretarias Municipais e projetos institucionais, atingindo um público total de 15.461 pessoas, sendo que $80 \%$ deste foram de estudantes.

Entre os anos de 2015 e 2017 houve um crescimento expressivo no quantitativo das formações conforme demonstra o gráfico a seguir:

Gráfico 1 - Educação, Gênero e Sexualidade: Formações Pedagógicas (2015-2018)

\section{Gráfico 1 - Educação, Gênero e sexualidade}

\section{Educação, Gênero e Sexualidade}

Formações Pedagógicas (2015-2018)

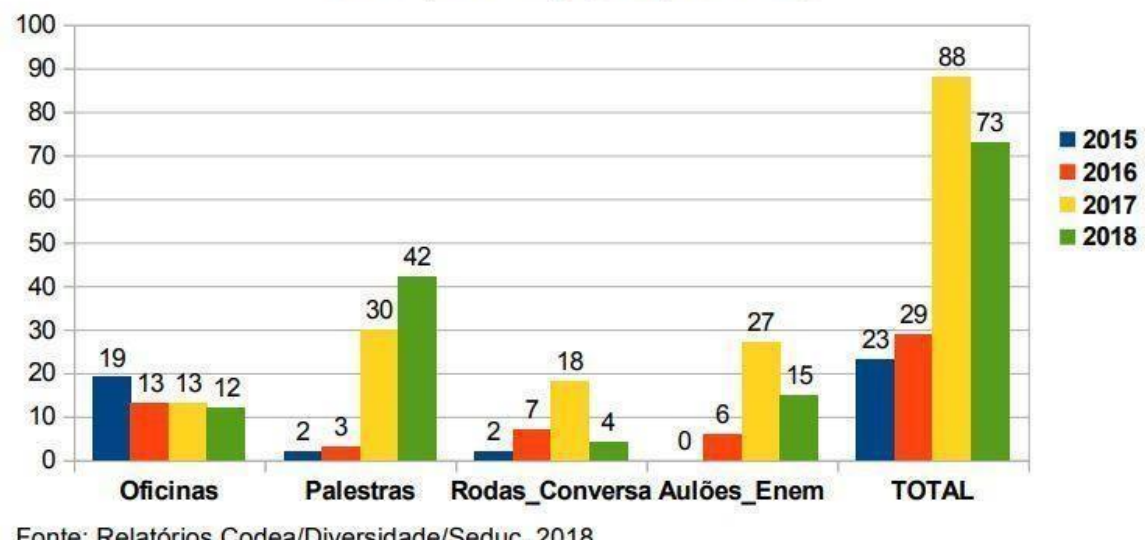

Fonte: Relatórios Codea/Diversidade/Seduc, 2018

Fonte: Autoria Própria

Conforme demonstrado no Gráfico 1, o maior quantitativo de formações do tipo oficinas ocorreu no ano de 2015, 19 ao todo, mantendo um número menor nos anos subsequentes, 13 nos anos de 2016 e 2017 e 12 no ano de 2018. Durante os anos de 2017 e 2018 as idas às Credes se deu principalmente em função das etapas regionais do projeto Escola, Espaço de Reflexão ${ }^{21}$. A equipe foi convidada para palestrar em mesas de debate e ministrar oficinas com os públicos participantes.

A queda no ritmo das formações entre os anos de 2017 e 2018 se deu em razão da falta de repasse de recursos para que as Credes/Sefor planejassem e executassem regionalmente suas próprias atividades formativas e a uma fraca

\footnotetext{
${ }^{21}$ Fonte: https://www.opovo.com.br/jornal/opiniao/2018/05/a-escola-e-espaco-de-reflexao.html
} 
articulação realizada entre a Seduc e suas Coordenadorias Regionais de Educação, secundarizando as temáticas de gênero e sexualidade. Ainda assim, de todas as vinte regionais de educação do interior do Estado e das três Superintendências das Escolas Estaduais de Fortaleza, somente as regionais 05 (Tianguá) e 12 (Quixadá) não passaram por nenhum processo formativo no período de 2015-2018.

Nas formações ministradas em cada regional participavam pelo menos um gestor e um professor de cada escola estadual localizada em cada um dos municípios, sob cobertura de sua respectiva Coordenadoria Regional de Desenvolvimento da Educação. Tomando por base os dados obtidos junto a Seduc percebeu-se que na prática, a política de formação educacional para as questões de gênero e sexualidade desenvolvidas no período de 2015 a 2018, ocorreu principalmente em escolas, por intermédio de palestras temáticas, tendo como principal público-alvo os estudantes. Nos subtópicos a seguir será descrito cada formato formativo.

\section{Oficinas pedagógicas}

As oficinas pedagógicas eram ministradas para gestores escolares e professores diretores de turma (PDT), prioritariamente, tendo em vista a disciplina de formação cidadã lecionada por esses educadores trazer, em sua matriz curricular, conteúdos sobre educação sexual e diversidade de gênero. O objetivo das oficinas era discutir e sensibilizar os educadores para a necessidade de se promover a valorização da diversidade de gênero e sexualidade nos ambientes escolares. Elas tinham carga horária de 8h, estavam estruturadas em três módulos de acordo com os conteúdos trabalhados e assumiam uma abordagem dos direitos humanos ${ }^{22}$. Em 57 oficinas ministradas ao longo de 4 anos (2015-2018), 20 delas nas sedes das Crede/Sefor, foram capacitadas 1.912 pessoas, entre gestores, professores e outros profissionais da educação.

\footnotetext{
22 A abordagem da educação sexual dos Direitos Humanos problematiza, explicita e tenta desconstruir representações negativas socialmente impostas aos sujeitos e identidades excluídas (por classe, raça/etnia, sexo, gênero, sexualidade, orientação sexual, regionalidade). Vinculada a Declaração Universal dos Diretos Humanos assume comprometimento político por uma sociedade melhor, com menos desigualdade. (FURLANI, 2011)
}

Revista de Políticas Públicas e Gestão Educacional (POLIGES) - UESB-Itapetinga. ISSN: 2763-5716Ano 2020, Volume 1, número 1, set. - dez. de 2020. 


\section{Palestras temáticas}

Atividade formativa ministrada para gestores, professores e estudantes com duração média de 90 minutos. Essas palestras eram agendadas por ofício/e-mail pelas próprias escolas ou ofertadas, onde se registrava, via ouvidoria, situações de preconceito/discriminação de caráter sexista, homofóbico e/ou violência de gênero.

As temáticas mais recorrentes dessas palestras foram assédio sexual, relacionamentos abusivos, preconceito de gênero no mercado de trabalho, LGBTfobia, famílias plurais, igualdade de gênero, cuidados com a saúde masculina e direitos humanos e diversidade. Esse foi o formato de formação pedagógica mais expressivo no período de 2015-2018. Ao todo se realizaram 77 palestras, alcançando um público de 7.060 pessoas entre gestores, estudantes e docentes.

\section{Rodas de conversa}

As rodas de conversa eram realizadas, prioritariamente, com grupos de estudantes, nos quais eles escolhiam as temáticas a serem abordadas ou temas diversos. A proposta era que os/as discentes colocassem suas dúvidas, questionamentos, vivências relacionadas às relações de gênero e sexualidade. Apesar de ser o formato mais dispendioso, pois exigia a presença de toda a equipe para garantir uma melhor qualidade, respeitando um número limite de 25 participantes por facilitador/a, era considerado pela equipe o tipo de formação mais rica, pois havia o exercício da escuta que proporcionava inúmeras situações de incertezas, indagações, denúncias e experiências pessoais e coletivas feitas por alunos/as. Isso reforça a importância de a escola discutir, de forma clara, objetiva e fundamentada, as relações de gênero e diversidade sexual presentes entre nós. Os temas mais solicitados pelos/as estudantes eram sobre corpo, afetividade, diversidade sexual e homofobia, feminismo, violência contra mulher, transexualidade e relações de gênero e mercado de trabalho. Em 31 rodas de conversa executadas, chegou-se a um público de 3.295 pessoas, em sua maioria alunos e alunas.

Revista de Políticas Públicas e Gestão Educacional (POLIGES) - UESB-Itapetinga. ISSN: 2763-5716Ano 2020, Volume 1, número 1, set. - dez. de 2020. 


\section{Aulões ENEM}

No ano de 2016, a Secretaria da Educação do Estado do Ceará lançou a $1^{a}$ edição $^{23}$ do Enem Não Tira Férias ${ }^{24}$ e do \#FDScurtindoEnem ${ }^{25}$, como ações integrantes do Projeto Enem chego junto, chego bem ${ }^{27}$. Dentro dessas ações, a subárea de Educação, Gênero e Sexualidade iniciou a oferta de aulões preparatórios para o exame, tendo em vista que as temáticas de gênero são recorrentes no Enem, sobretudo, nas provas de Linguagens e Códigos e Ciências Humanas (Souza, 2018). Os aulões, com duração de 90 minutos, objetivavam aprofundar as discussões do campo de estudos de gênero através da resolução de questões de edições anteriores do exame e de questões simuladas seguindo o padrão das provas. Foram realizadas, entre 2016 e 2018, 48 aulões com a participação de 3.194 estudantes.

A mobilização, sensibilização e divulgação das ações da EGS eram feitas via ofícios expedidos pela Coordenadora da Codea/Diversidade; por contatos via e-mail e telefone, feitos pelos integrantes da equipe em questão; pelas notícias publicadas pelo site oficial da Seduc e atendendo às demandas vindas das Credes/Sefor. Essas eram recebidas das escolas, espontaneamente, e/ou por ouvidorias direcionadas à Coordenadoria da Diversidade e Inclusão Educacional.

\footnotetext{
${ }^{23}$ FONTE:

http://blogs.diariodonordeste.com.br/zonanorte/sobral_/sobral-enem-nao-tira-feriasfortalecera-aprendi zagem-dos-alunos-da-3aserie-do-ensino-medio/

${ }^{24}$ Realização de aulões preparatórios para o Enem durante o mês de julho. Os aulões ocorriam por escolas-pólos.

${ }^{25}$ Projeto da Secretaria da Educação alterna aulas com atividades culturais e de lazer durante os fins de semana (https://www.seduc.ce.gov.br/2017/09/14/seduc-lanca-fdscurtindoenem-nesta-sexta-feira). ${ }^{27} \mathrm{O}$ Enem Chego Junto, Chego Bem tem a finalidade de mobilizar, motivar e preparar os alunos da Rede Pública Estadual para a realização do Exame. A ação acontece durante todo o ano letivo em seis etapas: (1) Auxílio na organização dos documentos necessários para realizar a inscrição; (2) Apoio nos dias de inscrição; (3) Eventos motivacionais e de orientação vocacional; (4) Ações pedagógicas de estudo para o Enem; (5) Realização do \#enemvou2dias, com auxílio no transporte e pontos de apoio aos alunos nos dois dias de provas; e (6) Orientações para o acesso ao Ensino Superior. Disponível em:

https://www.ceara.gov.br/2016/10/07/preparacao-dos-alunos-da-rede-estadual-para-o-enem2016-che ga-a-reta-final/).
}

Revista de Políticas Públicas e Gestão Educacional (POLIGES) - UESB-Itapetinga. ISSN: 2763-5716Ano 2020, Volume 1, número 1, set. - dez. de 2020. 


\section{Para concluir (...)}

Ambientes escolares carregados de situações que naturalizam práticas preconceituosas e discriminatórias não contribuem para a formação de cidadãos que respeitem às várias dimensões humanas e sociais. Dentre essas práticas estão os preconceitos de caráter sexista e homofóbico. Nesse contexto, para disseminar uma reflexão de combate às situações discriminatórias citadas, a Secretaria da Educação do Estado do Ceará, através da subárea de Educação, Gênero e Sexualidade da Coordenadoria da Diversidade e Inclusão educacional, desenvolveu durante a $1^{\text {a }}$ gestão do governador Camilo Santana (2015-2018), um trabalho de sensibilização e formação de gestores, professores e estudantes, a fim de colaborar com a construção de um clima escolar mais sadio, envolvente e valorizador da diversidade humana, especialmente em suas relações de gênero e sexualidade.

Este artigo versou sobre as ações de governo do Estado do Ceará para as políticas de educação em gênero e sexualidade durante a gestão Camilo Santana (2015-2018) e teve como objetivo descrever as principais atividades desenvolvidas pela Secretaria da Educação do Estado do Ceará (Seduc).

Metodologicamente utilizou-se a análise documental de planos de trabalho, relatórios e dossiês produzidos pela Seduc e das mensagens governamentais pronunciadas durante a gestão governamental do período em questão (2015-2018) para alcançar o objetivo deste estudo.

Durante o período de 2015 a 2018, a Seduc desenvolveu ações relevantes no que concerne à política educacional para as temáticas de gênero e sexualidade. Dentre essas ações, a formação de gestores e professores, por meio de oficinas pedagógicas e o atendimento às escolas, através, principalmente, de palestras com estudantes, foi a mais expressiva. Mesmo sem recursos financeiros, com uma equipe técnica reduzida e sem prioridade dentro do plano de governo executado pela Secretaria, foram realizadas 213 formações em Crede/Sefor, escolas das redes públicas, secretarias municipais de educação e projetos institucionais, alcançando diretamente um público de 15.461 pessoas e contemplando 134 municípios do Estado do Ceará.

Revista de Políticas Públicas e Gestão Educacional (POLIGES) - UESB-Itapetinga. ISSN: 2763-5716Ano 2020, Volume 1, número 1, set. - dez. de 2020. 
Também foram organizados seminários temáticos, ofertados cursos de aperfeiçoamento, publicado trabalhos e concedidas entrevistas. $O$ intuito foi de mobilizar, sensibilizar, divulgar, articular e apoiar as ações da Educação, Gênero e Sexualidade e os projetos curriculares de promoção da igualdade de gênero, o respeito à diversidade sexual e à dignidade humana, desenvolvidos pela Seduc e pelas escolas da rede estadual. Entretanto, observou-se que todo esse rol de ações se deu de formas pontuais e por vezes isoladas do ponto de vista institucional.

Os resultados apontam que a política de formação pedagógica com o recorte temático citado é inovadora, relevante e, sobretudo, uma política de resistência, porém insipiente e desarticulada. A política educacional do estado do Ceará na área estudada carece de maior conhecimento e aplicabilidade dentro do cotidiano escolar. É uma política ainda não prioritária dentro da agenda governamental e de alcance limitado, especialmente por causa da incipiência de sua articulação interinstitucional e da ausência de aportes financeiros.

\section{Referências}

BARDIN, L. Análise de conteúdo. Lisboa: edições 70, 1977.

BRASIL. Plano Nacional de Educação 2014-2024. Lei no 13.005, de 25 de junho de 2014. Brasília: Edições Câmara, 2014.

CEARÁ. Plano de Governo Os 7 Cearás: síntese do Processo de Planejamento Participativo para elaboração do Plano de Governo do Estado do Ceará 2015/2018. Fortaleza: [s.n], 2015. Disponível em:

<http://ptceara.org.br/images/conteudo/file/1_PlanodeGovernoCE2014.pdf>. Acesso em: 12 set. 2016.

CEARÁ. Diário oficial do Estado. Decreto n. 32.18., série 3, ano IX, n.069, 07/08/2017, p.6- 7.

CONSELHO NACIONAL DE EDUCAÇÃO. Diretrizes Curriculares Nacionais para o Ensino Médio. Resolução № 2, de 30 de janeiro de 2012. Brasília:MEC,2012.

Disponível em:

<http://portal.mec.gov.br/escola-de-gestores-da-educacao-basica/323-secretarias-11 2877938/orgaos-vinculados-82187207/17417-ceb-2012>. Acesso em: 01 set. 2016. 
CONSELHO NACIONAL DE EDUCAÇÃO. Define o uso do nome social de travestis e transexuais nos registros escolares. Resolução $n^{\circ}$ 01, de 19 de janeiro de 2018. Brasília:MEC,2018. Disponível em:

<http://portal.mec.gov.br/component/content/article?id=59331\#: :text=Resolu\%C3\% A7\%C3\%A30\%20CNE\%2FCP\%20n\%C2\%BA\%201,e\%20transexuais\%20nos\%20re gistros \%20escolares>. Acesso em: 03 dez. 2018.

FEITOSA, C. Políticas Públicas LGBT e construção democrática no Brasil. Curitiba: Appris, 2017.

FURLANI, J. Educação sexual na sala de aula: relações de gênero, orientação sexual e igualdade étnico-racial numa proposta de respeito às diferenças. Belo Horizonte: Autêntica, 2011.

SEDUC. Coordenadoria de Diversidade e Inclusão Educacional - CODIN. s/d. Disponível em:

$<$ https://www.seduc.ce.gov.br/coordenadoria-de-diversidade-e-inclusao-educacionalc odin/>. Acesso em 17 mar. 2021.

SOUZA, H. H. Plano Estadual de Educação do Ceará: gênero e sexualidade entre avanços e retrocessos. Fortaleza: CONEDU, 2016. Disponível em:

http://www.editorarealize.com.br/artigo/visualizar/21943. Acesso em: 03 dez. 2018.

SOUZA, H. H. ENEM, Gênero e Sexualidade. Mossoró: EdUERN, 2018. Disponível em: https://senacem.uern.br/files/users/lavinia/ANAIS/gd11.pdf. Acesso em: 10 dez. 2018.

VIANNA, C. O movimento LGBT e as políticas de educação de gênero e diversidade sexual: perdas, ganhos e desafios. Educ. Pesqui., São Paulo, v. 41, n. 3, p. 791806, jul./set. 2015. Disponível em:

<https://www.scielo.br/scielo.php?pid=S1517-97022015000300791\&script=sci_abstr act\&tlng=pt>. Acesso em: 18. Mar. 2021.

\section{Homero Henrique de Souza}

Doutorando em Sociologia. Mestre em Políticas Públicas. Professor efetivo da Rede Estadual de Ensino do Ceará e da Rede Municipal de Maracanaú-CE. Correio eletrônico: homerogeografia@gmail.com.

\section{Arliene Stephanie Menezes Pereira}

Doutoranda em Educação. Mestra em Educação Física pela Universidade Federal do Rio Grande do Norte (UFRN). Docente do Instituto Federal de Educação, Ciência e Tecnologia do Ceará (IFCE). Integrante do grupo de pesquisa Práticas Educativas, Memórias e Oralidades (PEMO). Correio eletrônico: stephanie_ce@hotmail.com. 


\section{Ana Carolina Braga de Sousa}

Doutoranda em Educação. Professora efetiva da Rede Estadual de Ensino do Ceará.

Integrante do grupo de pesquisa Práticas Educativas Memórias e Oralidades (PEMO). Correio eletrônico: carolbraga30@yahoo.com.br.

\section{Zuleide Fernandes de Queiroz}

Pós-doutora em Educação pela Universidade Federal do Rio Grande do Norte (UFRN). Doutora em Educação pela Universidade Federal do Ceará (UFC). Docente da Universidade Regional do Cariri (URCA), da Faculdade de Medicina de Juazeiro do Norte (FMJ) e dos Programas de Mestrado: Mestrado Profissional em Educação (MPEDU)- Departamento de Educação da URCA, PROFHISTÒRIA - Departamento de História da URCA e PRODER/UFCA. Correio eletrônico: zuleidefqueiroz@gmail.com. 